\title{
Composição química, caracterização e quantificação da população de microrganismos em capim-elefante cv. Cameroon (Pennisetum purpureum, Schum.) e suas silagens ${ }^{1}$
}

\section{Odilon Gomes Pereira ${ }^{2}$, Karina Dosualdo Rocha ${ }^{3}$, Celia Lucia de Luces Fortes Ferreira ${ }^{4}$}

\author{
1 Parte da tese de Mestrado da segunda autora, financiada pelo CNPq. \\ 2 Departamento de Zootecnia/UFV, Viçosa, MG, CEP: 36571-000. Bolsista do CNPq \\ 3 Zootecnista, Viçosa, MG, CEP: 36571-000. Bolsista do CNPq. \\ ${ }^{4}$ Departamento de Tecnologia de Alimentos/UFV, Viçosa, MG, CEP: 36571-000.
}

RESUMO - Avaliaram-se o pH, a relação nitrogênio amoniacal/nitrogênio total $\left(\mathrm{N}^{-} \mathrm{NH}_{3}\right)$, a composição química e a digestibilidade in vitro da MS (DIVMS) e as populações microbianas de silagens de capim-elefante produzidas ou não com inoculantes enzimo-bacterianos, em seis períodos de fermentação (1, 3, 7, 14, 28 e 56 dias), utilizando-se silos laboratoriais. Foi usado um arranjo fatorial $6 \times 3$ (seis períodos de fermentação x três inoculantes), em um delineamento inteiramente casualizado, com três repetições. Avaliaram-se os seguintes inoculantes microbianos: controle (sem inoculante), Sil All C4 (Alltech do Brasil) e Bacto Silo C Tropical (Katec). Os teores de PB, FND e FDA, foram influenciados apenas pelo período de fermentação, enquanto para a DIVMS observou-se efeito da interação inoculante $\times$ período. Para o pH observou-se efeito de inoculante e de período, estimando-se reduções de 0,5769; 0,62327 e 0,80218 unidades/dia de fermentação para as silagens controle e tratadas com Sil All e Bacto Silo, respectivamente. Para o teor de $\mathrm{N}-\mathrm{NH}_{3}$, observou-se efeito da interação inoculante $\times$ período. A população de bactérias ácido lático no capim antes da ensilagem foi de $10^{4} \mathrm{ufc} / \mathrm{g}$ de forragem fresca, atingindo valor máximo da ordem de $10^{8} \mathrm{ufc} / \mathrm{g}$ de silagem, para a silagem controle, aos 14 dias de fermentação, e para as silagens tratadas com inoculantes, aos 7 dias. As enterobactérias não foram detectadas a partir do terceiro dia, apresentando valor máximo de $10^{4},<10$ e $10^{3}$ ufc/g para as silagens controle, Sil All e Bacto Silo C Tropical, respectivamente.

Palavras-chave: bactérias ácido-láticas, enterobactérias, leveduras, mofos, nitrogênio amoniacal, pH

\section{Chemical composition, characterization, and population of microorganisms on elephantgrass "Cameroon" (Pennisetum purpureum, Schum) and its silages}

\begin{abstract}
Values of $\mathrm{pH}$, ammonia nitrogen/total nitrogen $\left(\mathrm{NH}_{3}-\mathrm{N}\right)$, chemical composition, in vitro DM digestibility (IVDMD) and microbial populations of elephantgrass silages produced with enzymatic-bacterial inoculants, were evaluated in six fermentation periods $(1,3,7,14,28$, and 56 days), using laboratory silos. A 6 x 3 (six fermentation periods x three inoculants) factorial arrangement of treatments in a completely randomized design, with three replicates, was used. The following bacterial inoculants were evaluated: control (without inoculant), Sill All C4 (Alltech of Brazil) and Bacto Silo Tropical C (Katec). The CP, NDF and ADF contents were affected only by the fermentation period. The IVDMD, however, was affected by the inoculant $\times$ fermentation period interaction. The IVDMD concentration, however, was affected by the interaction between inoculant and fermentation period. There was a significant effect of inoculant and period on $\mathrm{pH}$ value, being observed reduction of $0.5769 ; 0.62327$, and 0.80218 units/day of fermentation for the control silage, silage treated with Sil All, and Bacto Silo, respectively. It was observed inoculant $\times$ fermentation period interaction for $\mathrm{NH}_{3}-\mathrm{N}$. The lactic acid bacteria population in the grass before ensiling was $10^{4} \mathrm{cfu} / \mathrm{gram}$ of fresh forage, reaching maximum value of $10^{8} \mathrm{cfu} / \mathrm{gram}$ of fresh silage at 14 days of fermentation to the control silage, and at 7 days of fermentation to the silages treated with inoculant. The enterobacter were not detected after the third day of fermentation and the maximum values of $10^{4},<10$, and $10^{3} \mathrm{cfu} /$ gram were registred for the silage to control, Sil All, and Bacto Silo Tropical C silages, respectively.
\end{abstract}

Key Words: ammonia nitrogen, enterobacter, lactic acid bacteria, molds, pH, yeasts

\section{Introdução}

Entre as forrageiras tropicais, o capim-elefante tem se destacado como uma das espécies mais promissoras e de maior potencial para a ensilagem, em virtude do satisfatório teor de carboidratos solúveis (Vilela, 1990), fácil cultivo, da boa aceitabilidade e do alto rendimento forrageiro (Tosi et al., 1995).

A ensilagem tem como principal objetivo maximizar a preservação original dos nutrientes encontrados na forra- 
gem fresca, durante o armazenamento, com o mínimo de perdas de MS e energia. É necessário, portanto, que a respiração da planta e sua atividade proteolítica, bem como a atividade clostrídica e o crescimento de microrganismos aeróbios, sejam limitadas.

Além do manejo adequado, a planta ao ser colhida deve apresentar teor de umidade ideal para a ocorrência de compactação ótima da massa ensilada e manutenção dos nutrientes, bem como o teor de carboidratos solúveis deve ser suficiente para promover adequada fermentação lática. Os substratos disponíveis para a fermentação são usados por microrganismos que utilizam rotas metabólicas diferenciadas, com a conseqüiente produção de ácido lático, principal produto da fermentação de bactérias láticas, ou de outros produtos como etanol e $\mathrm{CO}_{2}$, que são indesejáveis, tanto pela perda de energia no processo fermentativo da silagem quanto por ser um composto neutro para a flora ruminal (Van Soest, 1994). Portanto, um número adequado de bactérias láticas é necessário para garantir boa produção de ácido lático, promovendo queda mais rápida no $\mathrm{pH} \mathrm{e}$ inibindo a atividade de microrganismos deletérios à silagem, como enterobactérias, bactérias clostrídicas e outros.

O estudo da flora epifítica ou flora original das plantas, segundo Pahlow (1989), tem revelado resultados variáveis quanto à composição e ao número de microrganismos, uma vez que estão sujeitos aos elementos do clima, os quais são influenciados pela localização geográfica onde os estudos são conduzidos. Desse modo, os elementos do clima e a composição das plantas irão interferir diretamente nos vários complexos bioquímicos e processos microbiológicos que transcorrem desde o momento da colheita da forragem até o fornecimento da silagem ao animal.

A utilização dos açúcares durante a fermentação ocorre por um processo competitivo entre as bactérias láticas e vários outros grupos de microrganismos. $\mathrm{Na}$ fase inicial do processo de ensilagem, ocorre a proliferação de bactérias anaeróbias facultativas produtoras de ácido acético (enterobactérias) e de outras bactérias láticas heterofermentativas. Estas bactérias produzem etanol, ácido acético, ácido lático e $\mathrm{CO}_{2}$, utilizando glicose, frutose, xilose e ribose como substratos. A produção desses ácidos, principalmente de ácido lático, reduz o $\mathrm{pH}$, e, quando este é inferior a 5, o número dessas bactérias decresce e as bactérias láticas homofermentativas, ou seja, aquelas cujo produto principal é o ácido lático dominam a fermentação (McAllister \& Hristov, 2002).

Para se obter efetiva fermentação do material ensilado, têm-se adotado algumas estratégias visando à produção de altos níveis de ácido lático e ao rápido abaixamento do $\mathrm{pH}(<4,2)$, durante a fermentação. Neste contexto, o uso de aditivos, como os inoculantes bacterianos, destaca-se como alternativa disponível, pois, segundo Filya et al. (2000), são produtos seguros, não corrosivos e não poluentes, fáceis de serem manuseados e, portanto, considerados produtos naturais.

A utilização de culturas microbianas que controlam a fermentação por vias metabólicas de degradação de substratos que sejam energeticamente mais eficientes é considerada fundamental (Daeschel et al., 1987), pois inoculantes microbianos desenvolvidos a partir da própria planta a ser ensilada tem revelado melhor padrão fermentativo e maior recuperação da MS ensilada. Portanto, pesquisas de identificação da flora epifítica da forrageira são essenciais antes da recomendação do uso de inoculantes microbianos (Pahlow, 1989; Pitt, 1990).

O uso de inoculantes enzimo-bacterianos vem sendo difundido em todo o mundo, como alternativa capaz de favorecer a fermentação. No entanto, em condições tropicais, os estudos que relacionam estes inoculantes à fermentação e, ou, ao desempenho de animais ainda são escassos, indicando a necessidade de pesquisas envolvendo essas características.

Conduziu-se este trabalho objetivando-se quantificar e caracterizar as populações microbianas e avaliar a composição química, o pH, a relação nitrogênio amoniacal/nitrogênio total e a digestibilidade in vitro da MS (DIVMS) de silagens de capim-elefante produzidas ou não com inoculantes enzimo-bacterianos.

\section{Material e Métodos}

O capim-elefante cv. Cameroon foi obtido a partir de uma capineira já estabelecida em uma área do Departamento de Zootecnia, da Universidade Federal de Viçosa (UFV), em Viçosa, MG. A cidade de Viçosa está situada a $20^{\circ} 45^{\prime}$ de latitude sul, $42^{\circ} 51^{\prime}$ de longitude oeste e $657 \mathrm{~m} \mathrm{de}$ altitude, apresentando precipitação média anual de $1.341 \mathrm{~mm}$, dos quais cerca de $86 \%$ ocorrem nos meses de outubro a março. A temperatura média das máximas é de $26,1^{\circ} \mathrm{C}$ e a média das mínimas, de $14,0^{\circ} \mathrm{C}$. O clima da região é classificado como "Cwa", segundo classificação proposta por Köepen (1948).

Utilizou-se um arranjo fatorial $6 \times 3$, seis períodos de fermentação (1, 3, 7, 14, 28 e 56 dias) e três inoculantes (controle, Sil All C4 e Bacto Silo C Tropical), em um delineamento inteiramente casualizado, com três repetições, para avaliação dos teores de $\mathrm{PB}$, da relação nitrogênio amoniacal/nitrogênio total $\left(\mathrm{N}-\mathrm{NH}_{3}\right)$ e do pH. Para avaliação dos constituintes fibrosos e da DIVMS, consideraram-se apenas quatro períodos de fermentação (1, 14, 28 e 56 dias). 
O capim foi cortado quando apresentava cerca de 100 dias de rebrotação e altura de 2,5 m, com auxílio de facão, rente ao solo, e, em seguida, picado em ensiladeira estacionária, previamente regulada para o tamanho de partícula igual a 2,0 cm. Os inoculantes comerciais avaliados foram: Sil-All C4, da Alltech do Brasil, contendo os seguintes níveis de garantia: Enterococcus faecium, Lactobacillus plantarum e Lactobacillus salivaris (10 bilhões UFC/g), enzimas celulase e hemicelulase a 5\%, e Bacto Silo C Tropical, da Katec Agrotécnica LTDA, com a seguinte composição: complexo bacteriano em alta concentração e complexo enzimático amilolítico. Os inoculantes foram adicionados ao material picado, com o auxílio de um pulverizador, com capacidade para $2 \mathrm{~L}$, respeitando-se as recomendações dos fabricantes.

O material foi acondicionado em silos de PVC $(40 \mathrm{~cm}$ de altura e $10 \mathrm{~cm}$ de diâmetro), dotados de válvula de Bünsen, com capacidade para aproximadamente $2 \mathrm{~kg}$ de forragem, com base na matéria natural. Em seguida, os silos foram fechados, pesados e armazenados em área coberta, em temperatura ambiente, até o momento de abertura, compreendido pelos períodos de fermentação de $1 ; 3 ; 7 ; 14 ; 28$ e 56 dias.

As análises microbiológicas foram realizadas no Laboratório de Forragicultura do Departamento de Zootecnia da UFV, no material antes da ensilagem e nas silagens correspondentes aos diferentes períodos de fermentação, tomando-se uma amostra composta das três repetições de campo. A contagem microbiana foi efetuada em duplicata e os dados obtidos foram analisados conforme os procedimentos adotados por González \& Rodriguez (2003). Aos $50 \mathrm{~g}$ de amostra foram adicionados $450 \mathrm{~mL}$ de água destilada, procedendo-se, em seguida, à mistura em liquidificador industrial por cerca de 1 minuto. Da solução obtida, pipetou-se $1 \mathrm{~mL}$ ou $0,1 \mathrm{~mL}$, com diluições que variaram de $10^{-1}$ a $10^{-9}$, usando-se garrafas para água de diluição contendo 99,9 mL de solução tampão fosfato, com pH de 7,2 . O plaqueamento foi feito em duplicata para cada diluição e meio de cultura.

As possíveis alterações microbianas e as populações mais influentes no processo de fermentação das silagens avaliadas foram determinadas por meio de técnicas de culturas seletivas, consistindo nas seguintes denominações:

Ágar Nutriente (DIFCO, Detroit), para contagem total de microrganismos, após incubação por 48 horas, à temperatura de $35^{\circ} \mathrm{C}$;

Ágar Rogosa SL (DIFCO, Detroit), para contagem de lactobacilos após incubação por 48 horas, em estufa, à temperatura de $37^{\circ} \mathrm{C}$, sendo o $\mathrm{pH}$ do meio da cultura igual a 5,4

Ágar BDA, para contagem de leveduras e mofos, após incubação por 5-7 dias, à temperatura ambiente, sendo o pH do meio de cultura igual a 4,2; e

Ágar Violeta Red Bile (DIFCO, Detroit), para contagem de enterobactérias, após incubação por 24 horas, à temperatura de $35^{\circ} \mathrm{C}$;

Foram consideradas passíveis de contagem aquelas placas que apresentaram entre 30 e 300 ufc por placa de Petri. Os resultados foram obtidos por meio da média das duas placas, na diluição selecionada.

Por ocasião da abertura dos silos, efetuou-se nova pesagem destes e foram coletadas amostras de material de cada silo para determinações de $\mathrm{pH}$ e N-NH${ }_{3}$ (Bolsen et al., 1992). Para o $\mathrm{pH}$ foram coletadas sub-amostras de $25 \mathrm{~g}$ de silagem, às quais foram adicionados $100 \mathrm{~mL}$ de água destilada, permanecendo-se em repouso por duas horas, efetuando-se, em seguida, a leitura do pH. Em outra subamostra de $25 \mathrm{~g}$ de silagem, adicionaram-se $200 \mathrm{~mL}$ de uma solução de $\mathrm{H}_{2} \mathrm{SO}_{4} 0,2 \mathrm{~N}$, permanecendo em geladeira por 48 horas, fazendo-se em seguida, a filtragem em papel-filtro do tipo "Whatman 54". Esse filtrado permaneceu em geladeira até as determinações de $\mathrm{N}-\mathrm{NH}_{3}$.

Concomitantemente, as amostras originais e suas respectivas silagens foram submetidas à pré-secagem a $65^{\circ} \mathrm{C}$, por 72 horas, em estufa de ventilação forçada. Em seguida, foram trituradas em moinho estacionário tipo "ThomasWilley", utilizando-se peneira com malha de $1 \mathrm{~mm}$, e acondicionadas em frascos de vidro com tampas de plástico para análises posteriores.

Os materiais originais e as silagens foram avaliados quanto aos teores de $\mathrm{PB}$, carboidratos solúveis em água (CHOsol), FDN e FDA e à DIVMS, segundo recomendações de Silva \& Queiroz (2002).

Os dados obtidos foram submetidos às análises de variância e regressão, utilizando-se o programa SAEG, versão 8.0 (UFV, 2000). Para os fatores qualitativos, aplicou-se o teste Tukey, a 5\% de probabilidade, na comparação das médias.

A escolha das equações de regressão foi feita com base no coeficiente de determinação e na significância dos coeficientes de regressão, utilizando-se o teste t. Para avaliação do $\mathrm{pH}$, em função do período de fermentação, procedeu-se ao ajuste dos dados ao modelo não-linear: $Y t=A+B x e^{-c t}$, proposto por Hristov \& McAllister (2002), em que: A refere-se ao valor final de $\mathrm{pH} ; \mathrm{B}$, à queda total em $t$ tendendo ao infinito; e $\mathrm{C}$, à taxa de declínio da fração $\mathrm{B}$. 


\section{Resultados e Discussão}

O capim-elefante na ensilagem apresentou valores médios de 25,8; 5,2; 7,4; 77,7 e 54,3\% para MS, CHOsol, PB, FDN e FDA, respectivamente. O teor médio de MS do capimelefante nesta pesquisa assemelhou-se àquele preconizado (25\%) por McDonald et al. (1991), como condição necessária para que as perdas por efluentes no silo sejam minimizadas e, portanto, ocorra a manutenção dos nutrientes de suas silagens. O teor médio de $\mathrm{CHOsol}(5,2 \%)$ encontra-se abaixo do valor mínimo (8\%) estabelecido por esses autores para adequada fermentação. Contudo, é importante destacar que existe efeito da interação dos teores de CHOsol e MS sobre o padrão de fermentação da forragem ensilada.

Observou-se que o teor de PB das silagens foi influenciado apenas pelo período de fermentação. No entanto, nenhuma equação de regressão ajustou-se aos dados, registrando-se valor médio de 6,3\%. De certa forma, esse resultado já era esperado, uma vez que não existem expectativas de que os teores de proteína sejam alterados ao longo do período de fermentação. Contudo, os resultados encontrados na literatura não são consistentes. Silva (2001) não verificou variação no teor de PB de silagens de milho e de sorgo não tratadas com inoculantes, porém observou efeitos linear e quadrático, de período, sobre o teor de PB das silagens tratadas com os inoculantes Silobac e MaizeAll, respectivamente.

Os teores de FDN e FDA também foram influenciados apenas pelo período de fermentação; os dados de FDN ajustaram-se ao modelo quadrático: $\hat{\mathrm{y}}=78,2703-$ $0,153664^{* *} \mathrm{P}+0,0017132^{* * *} \mathrm{P}^{2}\left(\mathrm{R}^{2}=78,52\right)$, estimando-se valor mínimo de 74,82\% na MS, aos 44,84 dias de fermentação, e os de FDA, ao modelo linear $\hat{y}=53,797-0,0391723 *$ $\mathrm{P}\left(\mathrm{r}^{2}=74,82\right)$.

Meeske et al. (1999) também não encontraram diferenças entre os teores de FDN de silagens de Digitaria eriantha, tratadas ou não com inoculantes microbianos. No entanto, a redução da fração fibrosa nessas silagens pode ser indicativo de hidrólise ácida da hemicelulose, que, segundo McDonald et al. (1991), é atribuída à ação de enzimas da planta e de enzimas dos próprios microrganismos e à adição de enzimas por meio do inoculante microbiano.

A ausência de efeito de inoculantes contendo enzimas fibrolíticas sobre a fração fibrosa das silagens pode ser atribuída a vários fatores. Se um dos objetivos das enzimas for liberar substratos fermentescíveis para as bactérias ácidoláticas, elas devem ser ativas na fase inicial do proceso de ensilagem, a um $\mathrm{pH}$ alto $(5,5-6,4)$ e a temperaturas menores que ocorrerão posteriormente. Estas condições são comple- tamente diferentes daquelas requeridas pela maioria das enzimas celulases para ótima atividade ( $\mathrm{pH}$ de 4,5 e temperatura de $50^{\circ} \mathrm{C}$ ) (Kung Jr. et al., 2003). Área de superfície, sítios de ligação, teor de umidade e proteases das plantas podem também inibir a atividade enzimática. A redução significativa da fração fibrosa da forragem a glicose por um aditivo enzimático requer ação sinérgica entre as enzimas do complexo enzimático. A falta ou a menor concentração de uma ou mais enzimas no complexo pode explicar a pobre efetividade de algumas combinações de enzimas na modificação da composição ou da fermentação da silagem (Kung Jr. et al., 2003).

Observou-se efeito $(\mathrm{P}<0,05)$ da interação inoculante $\times$ período sobre a DIVMS (Tabela 1$)$. No último dia de fermentação, o menor valor $(\mathrm{P}<0,05)$ foi apresentado pela silagem produzida com o inoculante Bacto Silo, que, por sua vez, não diferiu $(\mathrm{P}>0,05)$ da controle.

Constatou-se efeito quadrático $(\mathrm{P}<0,05)$ de período de fermentação sobre a DIVMS da silagem não tratada, estimando-se valor máximo de 52,99\%, aos 33,99 dias de fermentação, segundo a equação $\hat{\mathrm{y}}=46,1828+0,400657^{*} \mathrm{P}-$ $0,0058963{ }^{* *} \mathrm{P}^{2}\left(\mathrm{R}^{2}=91,95\right)$. Para as silagens inoculadas, não se detectou efeito de período, registrando-se valores médios de 51,7 e 48,7\%, para as silagens tratadas com os inoculantes Sil All e Bacto Silo C Tropical, respectivamente.

Observou-se efeito de inoculante e de período para o $\mathrm{pH}$ (Tabela 2$)$, com o menor valor $(\mathrm{P}<0,05)$ para a silagem tratada com o inoculante Sil All, que não diferiu da silagem controle. No entanto, as três silagens apresentaram valores de $\mathrm{pH}$ que permitem classificá-las de muito boa qualidade fermentativa. Segundo Muck \& Kung Jr. (1997), os inoculantes obtiveram êxito em silagens de gramíneas e leguminosas de clima temperado, apresentando redução de pHem 59 a $64 \%$ dos experimentos avaliados.

Na Figura 1, notam-se taxas de decréscimos de 0,5796; 0,62327 e 0,80218 unidades por dia de fermentação no $\mathrm{pH}$ das silagens controle e daquelas produzidas com os inoculantes Sil All e Bacto Silo, respectivamente. A partir do terceiro dia, as silagens apresentaram valores médios de pH em torno de 4,2, indicando boa fermentação. Bernardes et al. (2005), em ensaio com Brachiaria brizantha cv. Marandu, observaram estabilização do $\mathrm{pH}$ a partir do quarto dia de ensilagem, em todos os tratamentos, que se estendeu até o último dia de avaliação (56 dias).

Hristov \& McAllister (2002) registraram taxas de declínio no $\mathrm{pH}$ de silagens de cevada não emurchecida, variando de 0,488 (inoculante A) a 0,525 unidades por hora (inoculante B). Meeske et al. (1999) também verificaram rápida queda no pH e valor mais baixo em silagem de Digitaria eriantha 
Tabela 1 - Médias de DIVMS de silagens de capim-elefante, em função de períodos de fermentação e inoculantes

Table 1 - Mean IVDMD of elephantgrass silages as a function of fermentation periods and microbial inoculants

\begin{tabular}{llcc}
\hline $\begin{array}{l}\text { Período (dias) } \\
\text { Period (days) }\end{array}$ & \multicolumn{3}{c}{$\begin{array}{c}\text { Inoculante } \\
\text { Microbial inoculant }\end{array}$} \\
\cline { 2 - 4 } & $\begin{array}{c}\text { Controle } \\
\text { Control }\end{array}$ & Sill All & Bacto Silo \\
\hline 1 & $46,2 \mathrm{~b}$ & $51,0 \mathrm{a}$ & $50,8 \mathrm{a}$ \\
14 & $51,7 \mathrm{ab}$ & $52,0 \mathrm{a}$ & $47,8 \mathrm{~b}$ \\
28 & $52,0 \mathrm{a}$ & $52,2 \mathrm{a}$ & $48,9 \mathrm{a}$ \\
56 & $50,8 \mathrm{ab}$ & $51,5 \mathrm{a}$ & $47,4 \mathrm{~b}$ \\
\hline
\end{tabular}

Médias seguidas por letras iguais, na mesma linha, não diferem $(P<0,05)$ pelo teste Tukey.

Means followed by the same letters within a row do not differ $(P<0.05)$ by Tukey test

Tabela 2 - Médias de pH das silagens de capim-elefante para os diferentes inoculantes microbianos

Table 2 - Average $\mathrm{pH}$ of elephantgrass silages with different microbial inoculant

\begin{tabular}{lccc}
\hline Item & \multicolumn{3}{c}{$\begin{array}{c}\text { Inoculante } \\
\text { Microbial inoculant }\end{array}$} \\
\cline { 2 - 4 } & $\begin{array}{c}\text { Controle } \\
\text { Control }\end{array}$ & Sill All & Bacto Silo \\
\hline $\mathrm{pH}$ & $3,96 \mathrm{ab}$ & $3,94 \mathrm{~b}$ & $4,02 \mathrm{a}$ \\
\hline
\end{tabular}

Médias seguidas por letras iguais, na mesma linha, não diferem $(P<0,05)$ pelo teste Tukey.

Means followed by the same letters within a row do not differ $(P<0.05)$ by Tukey test.

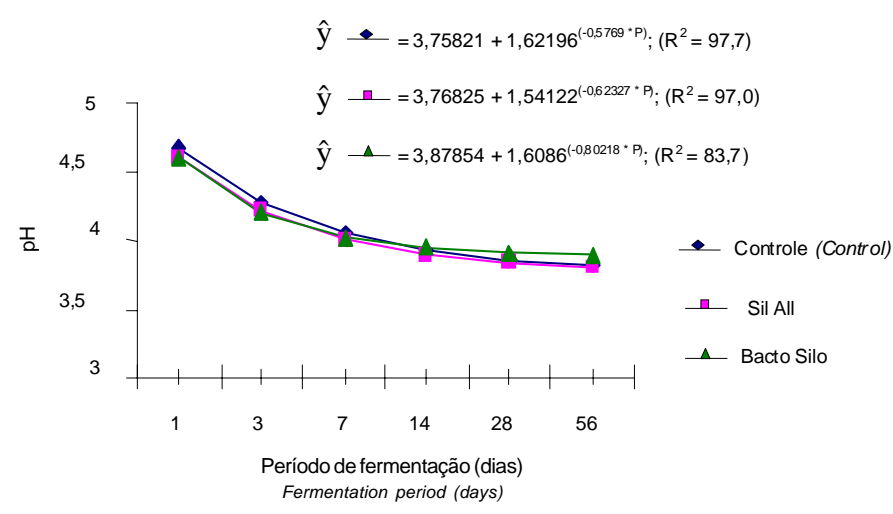

Figura 1 - Estimativa do $\mathrm{pH}$, em função de períodos de fermentação( $P)$, para as silagens de capim-elefante produzidas com diferentes inoculantes.

Figure 1 - Estimate of $\mathrm{pH}$ of elephantgrass silage produced with different bacterial inoculants as a function of fermentation periods $(P)$.

inoculada com Sil-All. Rápido decréscimo do pH e seu menor valor final podem auxiliar na diminuição da população de microrganismos deletérios à silagem, os quais produzem grande quantidade de ácidos acético e butírico.

Houve efeito $(\mathrm{P}<0,05)$ da interação inoculante $x$ período sobre o teor de $\mathrm{N}-\mathrm{NH}_{3}$ (Tabela 3). Constata-se
Tabela 3 - Teores médios de $\mathrm{N}-\mathrm{NH}_{3}$ de silagens de capim-elefante, inoculadas ou não, nos diferentes períodos de fermentação

Table 3 - $\quad$ Average concentration of $\mathrm{NH}_{3}-\mathrm{N}$ in elephantgrass silages as a function of fermentation periods and microbial inoculants

\begin{tabular}{lccc}
\hline $\begin{array}{l}\text { Período (dias) } \\
\text { Period (days) }\end{array}$ & \multicolumn{3}{c}{$\begin{array}{c}\text { Inoculante } \\
\text { Microbial inoculant }\end{array}$} \\
\cline { 2 - 4 } & $\begin{array}{c}\text { Controle } \\
\text { Control }\end{array}$ & Sill All & Bacto Silo \\
\hline 1 & $4,15 \mathrm{a}$ & $3,40 \mathrm{a}$ & $4,29 \mathrm{a}$ \\
3 & $3,19 \mathrm{a}$ & $3,98 \mathrm{a}$ & $3,93 \mathrm{a}$ \\
7 & $4,77 \mathrm{a}$ & $4,02 \mathrm{a}$ & $4,25 \mathrm{a}$ \\
14 & $8,33 \mathrm{~b}$ & $5,38 \mathrm{a}$ & $4,42 \mathrm{a}$ \\
28 & $7,71 \mathrm{a}$ & $7,42 \mathrm{a}$ & $6,42 \mathrm{a}$ \\
56 & $7,02 \mathrm{a}$ & $7,92 \mathrm{a}$ & $6,58 \mathrm{a}$ \\
\hline
\end{tabular}

Médias seguidas por letras iguais, na mesma linha, não diferem $(P<0,05)$ pelo teste Tukey.

Means followed by the same letters within a row do not differ $(P<0.05)$ by Tukey test.

que, somente aos 14 dias de fermentação, ocorreram diferenças $(\mathrm{P}<0,05)$ entre as silagens, registrando-se maior valor para a silagem controle. Observou-se efeito quadrático $(\mathrm{P}>0,05)$ de períodos de fermentação sobre o teor de $\mathrm{N}-\mathrm{NH}_{3}$ da silagem controle e daquela tratada com Sil All, cujos dados se ajustaram, respectivamente, às equações: $\hat{\mathrm{y}}=3,27317+0,3104 * \mathrm{P}-0,00438394 * \mathrm{P}^{2}$ $\left(R^{2}=79,00\right)$ e $\hat{y}=3,10257+0,204312 * P-0,00209833 * P^{2}$ $\left(\mathrm{R}^{2}=98,08\right)$. Todavia, para a silagem tratada com Bacto Silo, os valores de $\mathrm{N}-\mathrm{NH}_{3}$ não se ajustaram a nenhuma equação, registrando-se média de $4,98 \%$. Com base nos valores de $\mathrm{N}-\mathrm{NH}_{3}$ registrados neste estudo, infere-se que todas as silagens foram bem preservadas.

Considerando-se os valores das características fermentativas avaliadas ( $\mathrm{pH}$ e $\mathrm{N}-\mathrm{NH}_{3}$ ), pode-se afirmar que os inoculantes usados não foram efetivos em melhorar o padrão de fermentação das silagens. Segundo Kung et al. (2003), entre as prováveis explicações para falhas no uso de inoculantes à base de bactérias ácido lático, destacam-se: intensa competição da flora epifítica, baixa concentração de açúcar fermentescível, excesso de oxigênio, baixa atividade de água, falta de especificidade da cultura e, ou, problemas com a aplicação.

A população de enterobactérias atingiu valor máximo, no primeiro dia de fermentação para a silagem controle e aquela tratada com Bacto Silo, não sendo mais detectada do $7^{\circ}$ ao $28^{\circ}$ dia de fermentação (Tabela 4). Todavia, aos 56 dias de fermentação, a população destes microrganismos foi detectada novamente, em todas as silagens. Bernardes et al. (2005), avaliando silagens de Brachiaria brizantha na presença de polpa cítrica peletizada, também constataram maior população de enterobactérias no primeiro dia de fermentação, para todos os tratamentos. No entanto, 
Tabela 4 - População de microrganismos (log ufc/g forragem fresca) em capim-elefante antes e após a ensilagem, para os diferentes períodos de fermentação e inoculantes bacterianos

Table 4 - Microbial population (log cfu/g fresh forage) of elephantgrass prior and after ensiling as a function of fermentation periods and microbial inoculants

\begin{tabular}{|c|c|c|c|c|c|c|c|}
\hline \multirow[t]{2}{*}{$\begin{array}{l}\text { Inoculante } \\
\text { Inoculant }\end{array}$} & \multicolumn{7}{|c|}{$\begin{array}{l}\text { Período de fermentação } \\
\text { Fermentation period }\end{array}$} \\
\hline & $0^{1}$ & 1 & 3 & 7 & 14 & 28 & 56 \\
\hline \multirow{4}{*}{$\begin{array}{l}\text { Controle (Control) } \\
\text { Sil All } \\
\text { Bacto Silo }\end{array}$} & \multicolumn{7}{|c|}{ Enterobactérias (Enterobacter) } \\
\hline & 4,69 & 6,11 & 3,69 & ND & ND & ND & 2,44 \\
\hline & & 2,07 & ND & ND & ND & ND & 1,53 \\
\hline & \multicolumn{7}{|c|}{ Bactéria ácido lático (Lactic acid bacteria) } \\
\hline Controle (Control) & 4,92 & 6,04 & 5,91 & 6,88 & 8,34 & 7,38 & 7,17 \\
\hline Sil All & & 6,53 & 6,36 & 8,63 & 8,67 & 7,46 & 7,25 \\
\hline \multirow[t]{2}{*}{ Bacto Silo } & & 6,78 & 7,66 & 8,50 & 8,67 & 7,88 & 7,34 \\
\hline & \multicolumn{7}{|c|}{ Mofo e levedura (Molds and yeast) } \\
\hline & \multicolumn{7}{|c|}{ Contagem total (Total count) } \\
\hline Controle (Control) & 7,32 & 6,93 & 5,41 & 4,37 & 3,32 & 4,38 & 3,36 \\
\hline Sil All & & 6,46 & 5,72 & 5,61 & 5,49 & 7,39 & 4,64 \\
\hline Bacto Silo & & 7,41 & 5,53 & 5,04 & 4,55 & 6,82 & 4,54 \\
\hline
\end{tabular}

1 Planta antes da ensilagem (elephantgrass before ensiling).

ND = não detectável (not detected).

esses autores não detectaram a presença desses microrganismos a partir do quarto dia de fermentação.

Segundo Luis \& Ramirez (1988), normalmente as enterobactérias multiplicam-se até aproximadamente o $7^{\circ}$ dia de fermentação, quando são substituídas pelos grupos láticos. No entanto, esses microrganismos apresentam grande poder de sobrevivência e podem ser encontrados até os 30 dias de conservação, por terem habilidade de crescimento sob condições de anaerobiose e protegerem-se quando se encontram sob condições adversas, tal qual acontece sob valor de pH muito baixo. Bolsen et al. (1992) observaram populações de enterobactérias de $10^{4} \mathrm{e}$ $10^{2} \mathrm{ufc} / \mathrm{g}$ de silagem de milho, após 42 e 120 dias de fermentação, respectivamente. No entanto, pesquisas com silagens de diferentes plantas forrageiras têm demonstrado que esses grupos microbianos sofrem elevadas reduções até o $10^{\circ}$ dia de ensilagem (Meeske et al., 1999), podendo ou não desaparecer por completo até o final do período de conservação.

A população de bactérias produtoras de ácido lático (BAL), na planta de capim-elefante $\left(10^{4} \mathrm{ufc} / \mathrm{g}\right.$ forragem fresca), situa-se abaixo daquela preconizada por Muck (1991), de $10^{5} \mathrm{ufc} / \mathrm{g}$ de forragem fresca, como mínimo necessário para que perdas significativas deixem de ocor- rer ao longo da fermentação, em decorrência da fermentação lática das silagens. Meeske et al. (1999) encontraram população de lactobacilos da ordem de $10^{1} \mathrm{ufc} / \mathrm{g}$ de forragem fresca na planta de Digitaria eriantha, no tratamento controle, e Cai et al. (1998), analisando a microflora epifítica de capim-guiné (Panicum maximum Jacq), de $10^{3} \mathrm{ufc} / \mathrm{g}$ de forragem fresca. Nota-se que a população de BAL mostrou-se dominante em relação aos outros microrganismos, em todas as silagens, atingindo valor de $10^{8} \mathrm{ufc} / \mathrm{g}$, no $14^{\circ}$ dia de fermentação (Tabela 4).

A população inicial de leveduras e mofos encontra-se abaixo $\left(10^{3} \mathrm{ufc} / \mathrm{g}\right.$ de forragem fresca $)$ daquela encontrada para a população de leveduras por Meeske et al. (1999), na planta de Digitaria eriantha $\left(10^{6} \mathrm{ufc} / \mathrm{g}\right.$ de forragem fresca), e Silva (2001), em plantas de milho e de sorgo ( $10^{7} \mathrm{ufc} / \mathrm{g}$ de forragem fresca). No entanto, Cai et al. (1998) observaram população de leveduras e mofos da ordem de $10^{3} \mathrm{ufc} / \mathrm{g}$ de forragem fresca para o capim-guiné. Todavia, ao analisarem uma silagem após 44 dias de fermentação, Meeske et al. (1999) encontraram populações da ordem de $10^{3}$ e $10^{2}$ ufc/ g silagem, para as populações de levedura e mofo, respectivamente, valores semelhantes aos encontrados neste estudo. 
Avaliando-se os resultados dos testes fisiológicos de microrganismos isolados da planta de capim-elefante (Tabela 5), constata-se que as características de forma, arranjo, teste de gram, catalase e hidrólise da arginina caracterizam-nos como espécies pertencentes ao gênero Lactobacillus.

Quanto ao padrão fermentativo das estirpes isoladas e ao padrão de espécies do gênero Lactobacillus encontradas no Manual de Bergey (Sneath et al., 1986), todas as estirpes isoladas fermentaram os mesmos carboidratos (Tabela 6).

Ao analisar as características fisiológicas e o padrão fermentativo da estirpe isolada, pode-se indicar que esta se assemelha às características apresentadas pelas espécies Lactobacillus casei ssp casei e Lactobacillus casei ssp pseudoplantarum. No entanto, para que a espécie seja identificada, faz-se necessária a análise genotípica da estirpe isolada.

Tabela 5 - Caracterização de estirpes isoladas na planta de capim-elefante de acordo com parâmetros fisiológicos Table 5 - Characterization of isolated strains on elephantgrass using physiological parameters

\begin{tabular}{|c|c|c|c|c|c|c|c|}
\hline \multirow[t]{2}{*}{$\begin{array}{l}\text { Teste } \\
\text { Test }\end{array}$} & \multicolumn{7}{|c|}{$\begin{array}{l}\text { Estirpe isolada } \\
\text { Isolated strain }\end{array}$} \\
\hline & 1 & 2 & 3 & 4 & 5 & 6 & 7 \\
\hline Shape & Rod & Rod & Rod & Rod & Rod & Rod & Rod \\
\hline Arranjo & 2/fileira & 2/fileira & 2/fileira & 2/fileira & 2/fileira & 2/fileira & 2/fileira \\
\hline Arrangement & 2/row & 2/row & 2/row & 2/row & $2 /$ row & 2/row & $2 /$ row \\
\hline Arginina (Arginine) & - & - & - & - & - & - & - \\
\hline
\end{tabular}

Crescimento em diferentes $\mathrm{pH}$

Growth in different $\mathrm{pH}$

9,2

9,6

\begin{tabular}{lllllll}
\hline- & - & - & - & - & - & - \\
- & - & - & - & - & - & - \\
\hline
\end{tabular}

Crescimento em $\mathrm{NaCl}$

Growth in $\mathrm{NaCl}$

$\mathrm{NaCl} 3 \%$

$\mathrm{NaCl} 4 \%$

$\mathrm{NaCl} 5 \%$

$\mathrm{NaCl} 6.5 \%$

$21^{\circ} \mathrm{C}$

$30^{\circ} \mathrm{C}$

$37^{\circ} \mathrm{C}$

$45^{\circ} \mathrm{C}$

\begin{tabular}{|c|c|c|c|c|c|c|}
\hline+ & + & + & + & + & + & + \\
\hline
\end{tabular}

Crescimento em diferentes temperaturas $\left({ }^{\circ} \mathrm{C}\right)$ Growth in different temperatures $\left({ }^{\circ} \mathrm{C}\right)$

\begin{tabular}{|c|c|c|c|c|c|c|}
\hline+ & + & + & + & + & + & + \\
\hline+ & + & + & + & + & + & \\
\hline - & - & - & - & - & - & - \\
\hline
\end{tabular}

Crescimento em aerobiose/anaerobiose Growth in aerobic/anaerobic conditions

Aerobiose (Aerobic) Anaerobiose (Anaerobic)

+
+

+ Positivo (positive); - Negativo (negative). 
Tabela 6 - Padrão fermentativo das estirpes isoladas do capim-elefante e de espécies do gênero Lactobacillus Table 6 - Fermentation standard of isolated strains from elephantgrass and from species of lactobacillus genus

\begin{tabular}{|c|c|c|c|c|c|c|c|c|c|c|c|c|c|c|c|c|}
\hline & 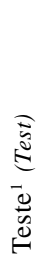 & 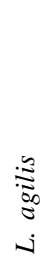 & 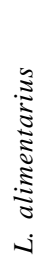 & 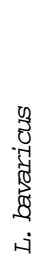 & 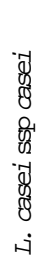 & 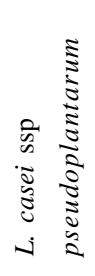 & 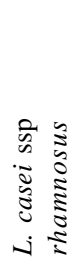 & 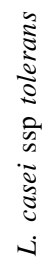 & 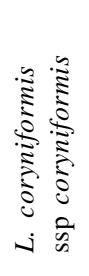 & 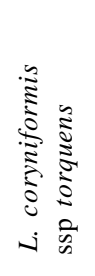 & 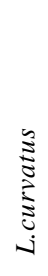 & 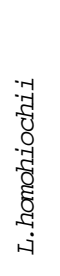 & 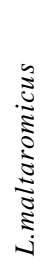 & $\begin{array}{l}\mathfrak{\Xi} \\
\stackrel{\Xi}{\Xi} \\
\stackrel{\Xi}{\Xi} \\
\text { J }\end{array}$ & $\begin{array}{l}\mathbb{3} \\
\vdots \\
\vdots \\
\vdots \\
\vdots \\
\vdots \\
\vdots\end{array}$ & 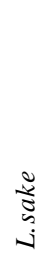 \\
\hline Amygdalin & + & + & $\mathrm{n}$ & - & + & + & + & - & - & - & - & - & + & $\mathrm{D}$ & + & + \\
\hline Arabinose & - & - & $\mathrm{D}$ & - & - & - & $\mathrm{D}$ & - & - & - & - & - & - & + & $\mathrm{D}$ & + \\
\hline Cellobiose & + & + & + & + & + & + & + & - & - & - & + & $\mathrm{D}$ & + & + & + & + \\
\hline Esculin & + & + & + & + & + & + & + & - & $\mathrm{D}$ & - & + & $\mathrm{N}$ & $\mathrm{N}$ & + & + & + \\
\hline Fructose & + & + & + & + & + & + & + & + & + & + & + & + & + & + & + & + \\
\hline Galactose & + & + & + & + & + & + & + & + & + & + & + & - & + & + & + & + \\
\hline Glucose & + & + & + & + & + & + & + & + & + & + & + & + & + & + & + & + \\
\hline Gluconate & + & - & + & + & + & + & + & - & + & + & + & - & $\mathrm{N}$ & - & + & + \\
\hline Lactose & + & + & - & + & D & + & + & + & $\mathrm{D}$ & + & $\mathrm{D}$ & - & + & + & + & + \\
\hline Maltose & + & + & + & + & + & + & + & - & + & + & + & + & + & + & + & + \\
\hline Mannitol & + & + & - & - & + & + & + & - & + & + & - & - & + & $\mathrm{D}$ & + & - \\
\hline Mannose & + & + & + & + & + & + & + & - & + & + & + & + & + & + & + & + \\
\hline Melezitose & - & + & - & - & + & + & + & - & - & $\mathrm{D}$ & - & - & + & - & $\mathrm{D}$ & - \\
\hline Melibiose & + & + & - & + & - & - & - & - & $\mathrm{D}$ & - & - & - & + & + & + & + \\
\hline Raffinose & - & + & - & - & - & - & - & - & $\mathrm{D}$ & - & - & - & - & + & + & - \\
\hline Ramnose & - & - & - & - & - & - & + & - & + & - & - & - & - & - & - & - \\
\hline Ribose & + & + & + & + & + & + & + & - & - & - & + & + & + & + & + & + \\
\hline Salicin & + & + & + & + & + & + & + & - & $\mathrm{D}$ & - & + & $\mathrm{D}$ & + & $\mathrm{D}$ & + & + \\
\hline Sorbitol & + & D & - & - & + & + & + & - & D & - & - & - & + & - & + & - \\
\hline Sucrose & + & + & + & + & + & + & + & - & + & - & - & - & + & + & + & + \\
\hline Trehalose & + & + & + & - & + & + & + & - & - & + & - & D & + & D & + & + \\
\hline Xilose & - & - & - & - & - & - & - & - & - & - & - & - & - & - & $\mathrm{D}$ & - \\
\hline
\end{tabular}

${ }^{1}$ Estirpe isolada da planta de capim-elefante (Isolated strain from elephantgrass plant). + $90 \%$ ou mais das estirpes são positivas ( $90 \%$ or more of the strains are positive).

D

D $-11-89 \%$ das estirpes são positivas (11-89\% of the strains are positive).

$\mathrm{N}$ - reação não determinada (Not detected). 


\section{Conclusões}

As silagens produzidas podem ser consideradas de boa qualidade fermentativa, considerando-se os baixos valores de $\mathrm{pH}$ e $\mathrm{N}-\mathrm{NH}_{3}$, não havendo a necessidade de inclusão de aditivos enzimo-bacterianos, uma vez que estes não alteram também a composição química e a digestibilidade das silagens.

As populações microbianas quantificadas nas silagens de capim-elefante são adequadas para a manutenção de uma boa fermentação no silo.

Com base nas características fisiológicas e no padrão fermentativo da estirpe isolada em plantas de capim-elefante antes da ensilagem, esta se assemelha às características apresentadas pelas espécies Lactobacillus casei ssp casei e Lactobacillus casei ssp pseudoplantarum

\section{Literatura Citada}

BERNARDES, T.F.; REIS, R.A.; MOREIRA, A.L. Fermentative and microbial profile of marandugrass ensiled with citrus pulp pellets. Scientia Agricola, v.62, p.214-220, 2005.

BOLSEN, K.K.; LIN, C.; BRENT, B.E. et al. Effect of silage additives on the microbial succession and fermentation process of alfalfa and corn silages. Journal of Dairy Science, v.75, n.11, p.3066-3083, 1992.

CAI, Y.; BENNO, Y.; OGAWA, M. et al. Influence of Lactobacillus spp. from an inoculant and of weissella and Leuconostoc spp from forage crops on silage fermentation. Applied and Environmental Microbiology, v.64, p.29822987, 1998.

DAESCHEL, M.A.; ANDERSON, R.E.; FLEMING, H.P. Microbial ecology of fermenting plant materials. FEMS Microbiology Reviews, v.46, n.3, p.357-367, 1987.

DIFCO MANUAL. 10.ed. Michigan: DIFCO Laboratories,1984. $1166 \mathrm{p}$.

FILYA, I.; ASHBELL, G.; HEN, Y. et al. The effect of bacterial inoculants on the fermentation and aerobic stability of whole crop wheat silage. Animal Feed Science and Technology, v.88, p.39-46, 2000.

GONZÁLEZ, G.; RODRÍGUEZ, A.A. Effect of storage method on fermentation characteristics, aerobic stability and forage intake of tropical grasses ensiled in round bales. Journal of Dairy Science, v. 86, n.3, p.926-933, 2003.

HRISTOV, A.N.; McALLISTER, T.A. Effect of inoculants on wholecrop barley silage fermentation and dry matter disappearance in situ. Journal of Animal Science, v.80, p.510-516, 2002.

KÖEPPEN, W. Climatologia. Buenos Aires: Panamericana, 1948. $478 \mathrm{p}$.

KUNG JR., L.; STOKES, M.R.; LIN, C.J. Silage additives. In: BUXTON, D.R.; MUCK, R.E.; HARRISON, J.H. (Eds). Silage science and technology. Madison: ASA-CSSA-SSSA, 2003. v.42, p.305-360.
LUIS, L.; RAMIREZ, M. Evolución de la flora microbiana en ensilaje de king grass. Pastos y Forrajes, v.11, p.249-253, 1988.

McAlLISTER, T.A.; HRISTROV, A.N. [2002]. The fundaments of making good quality silage. Disponível em: www.afns.ualberta.ca/hosted/wcd2000...s/chapter32.htm Acesso em: $1 / 9 / 2002$.

McDOnAlD, P.; HENDERSON, A.R.; HERON, S.J.E. The biochemistry of silage. 2.ed. Marlow: Chalcombe Publication, 1991. 340p.

MEESKE, R.; BASSON, H.M.; CRUYWAGEN, C.W. The effect of a lactic acid bacterial inoculant with enzymes on the fermentation dynamics, intake and digestibility of Digitaria eriantha silage. Animal Feed Science and Technology, v.81, n.3/4, p.237-248, 1999

MUCK, R.E. Silage fermentation. In: Mixed cultures in biotechnology. New York: McGrow Hill Inc., 1991. p.171204.

MUCK, R.E.; KUNG JR., L. Effects of silage additives on ensiling. In: SILAGE FIELD TO FEEDBUNK, 1997, Pennsylvania. Proceedings... New York: NRAES, 1997. n.99, p.187-199.

PAHLOW, G. Ecological studies of epiphytic lactic acid bacteria (Lab) on whole plant maize and in inoculated silage. In: FOOD FOR ThOUGHT, 2., 1989., Johnston. Proceedings... Johnston: Pionner Hi-Bred International, 1989.

PITT, R.E. The probability of inoculant effectiveness in alfalfa silages. Transactions of the ASAE, v.33, n.6, p.1771-1778, 1990.

SILVA, A.V. Populações microbianas em plantas de milho e sorgo, produtos da fermentação e desempenho de bovinos de corte, suplementados com suas silagens, tratadas com inoculantes microbianos. Viçosa, MG: Universidade Federal de Viçosa, 2001. 122p. Tese (Doutorado em Zootecnia) Universidade Federal de Viçosa, 2001

SILVA, D.J.; QUEIROZ, A.C. Análise de alimentos: métodos químicos e biológicos 3.ed. Viçosa, MG: Editora UFV, 2002. $235 \mathrm{p}$.

SNEATH, P.A.; MAIR, N.S.; SHARPE, M.E. et al. Bergey's manual of systematic bacteriology. 9.ed. Baltimore: Williams \& Wilkins, 1986. v. 2, p.1-35.

TOSI, H.; RODRIGUES, L.R.A.; JOBIM, C.C. et al. Ensilagem do capim-elefante cv. Mott sob diferentes tratamentos. Revista da Sociedade Brasileira de Zootecnia, v.24, n.6, p.909916, 1995.

UNIVERSIDADE FEDERAL DE VIÇOSA - UFV. SAEG - Sistema de análises estatísticas e genéticas. Versão 8.0. Viçosa, MG: 2000. 150p. (Manual do usuário).

Van SOEST, P.J. Nutritional ecology of the ruminant. 1.ed. Ithaca: Cornell University Press, 1994. 374p.

VILELA, D. Utilização do capim-elefante na forma de forragem conservada. In: SIMPÓSIO SOBRE CAPIM-ELEFANTE, 1990, Coronel Pacheco. Anais... Juiz de Fora: EMBRAPA-CNPGL, 1990. p.89-131. 